\title{
The Effects of Consumer Personality Types on the Attitudes and Usage of Self-Checkout Technology in the Retail Sector among 18-22 Years Old
}

\author{
Thomas W. Jackson ${ }^{1}$, Paul Parboteeah ${ }^{1} \&$ Siobhan Metcalfe-Poulton ${ }^{1}$ \\ ${ }^{1}$ Centre for Information Management, Loughborough University, Loughborough, UK \\ Correspondence: Thomas W. Jackson, Centre for Information Management, Loughborough University, \\ Loughborough, UK. E-mail: t.w.jackson@lboro.ac.uk
}

Received: October 21, 2013 Accepted: November 28, 2013 Online Published: March 24, 2014

doi:10.5539/ijms.v6n2p15 URL: http://dx.doi.org/10.5539/ijms.v6n2p15

\begin{abstract}
The aim of the research is to understand the relationship between personality types and the use of self-checkout machines (SCO) in retail. Understanding this relationship will provide different perspectives of how and why consumers interact with this technology in order to implement the technology for improved use. This research presents the theory behind technology acceptance, consumer personalities, technology anxiety and human interaction before creating a questionnaire to understand the relationship between SCO use and personality types. The findings show a relationship between personality types and attitudes towards and usage of SCO. A number of situational factors are also found to have a significant effect on consumers' decision to use SCO, of which speed and item quantity had a greater influence on attitudes and usage than personality type. As one of the first papers comparing personality types and the adoption of self-checkout technology, it provides a unique insight into how such technologies are used in retail. By understanding how different personalities view, and use, self-checkouts, they will be better able to optimise the customer experience when preparing to leave the store, and ultimately encourage them to return later.Research already exists that looks at self-service technology in different situations but little research exists that looks specifically at self-checkouts in retail environments. This paper addresses that lack by not only looking at attitudes towards self-check-outs, but also comparing those attitudes to personality types.
\end{abstract}

Keywords: kiosks, personality types, retail, self-checkout technology, technology adoption

\section{Introduction}

The automation of retail transaction has become increasingly common since the introduction of the automated teller machine (ATM) several decades ago. Self-service technology (SST) has continued to grow in the form of online banking, information kiosks, self-service petrol stations, and self-service machines in retail. As technologies continue to grow and become part of our daily lives, it is important to understand consumer reactions and willingness to adopt these new self-service technologies (Meuter et al., 2003). SST's are technological interfaces that enable customers to carry out tasks themselves without the assistance of an employee (Meuter et al., 2000). The notion of a service encounter usually creates an image of face-to-face interaction between a customer and an employee of a firm (Bitner, 1990). This image is now changing (Makarem et al., 2009) as advances in technology have created a surge in self-service technology options (Dabholkar et al., 2003). The growth in these self-service technologies could be a result of increased labour costs mixed with innovations in technology (Dabholkar, 1996).

Meuter et al. (2000) describes different types of SST's which are used for different purposes such as customer service, transactions, or self-help. These include telephone-based technologies, internet technologies, interactive free-standing kiosks, and CD technologies. Telephone-based technologies include telephone banking, support lines, mobile top-up, and telephone booking. Internet technologies can range from internet shopping and banking, to tracking packages, e-learning, and information searching. Interactive kiosks can be found in the form of ATMS, pay at the pump, and tourist information machines. Although some of these technologies have benefited customers, such as ATM's being available 24/7 and self-checkout's saving time, they have also been noted to cause frustration and dissatisfaction amongst customers (Parasuraman, 2000). Meuter et al. (2000) explains that because of the huge 
growth and wide variety of types of SST's, it is critical to understand customer's reactions to them, how they use them, and if they will use them in the future.

SCO's are interactive kiosks which allow customers to scan, pack, and pay for goods either by themselves or with little assistance from staff (Lee et al., 2010). SCO's were introduced over two decades ago (Webster, 2009) and were at first met with resistance from customers, which may have been because consumers were not ready to adopt the new technology or change their shopping behaviour (Dabholkar et al., 2003). A research study conducted by RBR revealed that in 2007 nearly 22,000 SCO units were sold globally, an increase of $34 \%$ from 2006, and by the end of 2007 a total of 70,000 units were installed globally, an increase of $35 \%$ on the previous year (Retail Banking Research, 2009). RBR's research also forecasts the number of SCO's to triple by 2011 to 28200 units. This suggests that a growing number of SCO's are being adopted by retailers. There are many studies that research into the various SST's but there are few which focus specifically on SCO. As SCO technology becomes increasingly more common in retail, it is important to understand the motivations for customers using this technology, and gain an understanding of the types of people who use and avoid SCO.

The aim of the paper is to discover and understand the relationship between personality types of consumers and how it affects their opinion, and use of, self-check-outs. This paper starts by looking at the personality characteristics of 18-22 years old, and their relationship with technology, human interaction and attitudes towards anxiety and risk. It then outlines the research design used to assess both attitudes towards, and use of, SCOs. The results and analysis form the next section of the paper, comparing the results to the existing literature on SCOs and their adoption and the paper finishes with the recommendations to improve the both the retailer use, and consumer uptake, of SCO technology.

\section{Theoretical Background}

To gain a better understanding of why consumers use or reject SCO, it is important to examine the research into the traits that are related to the adoption of SST and SCO.

\subsection{Technology Acceptance and Intention to Use}

The Technology Acceptance Model (TAM) (Davis et al., 1989) was developed to explain the adoption and use of technology and hypothesises that individuals' behavioural intention to use technology is determined by two beliefs: perceived ease of use and perceived usefulness. The perceived ease of use is the degree to which the individual believes using the technology will be effort-free, and perceived usefulness is the extent to which an individual believes a technology will enhance their performance when carrying out tasks (Venkatesh \& Bala, 2008). The two beliefs are said to be directly affected by external variables, such as system design characteristics and system features (Davis et al., 1989). This paper makes a theoretical contribution to the TAM based on Lee et al. (2010) who proposed that the intention to use a piece of technology is directly affected by consumers' traits, and indirectly affected by consumers' demographic factors. The main thesis of this paper is that whilst Lee et al. (2010) are correct at a high level, a more detailed understanding can be gained by mapping personality types into Lee et al.'s (2010) conceptual framework (as shown in Figure 1).

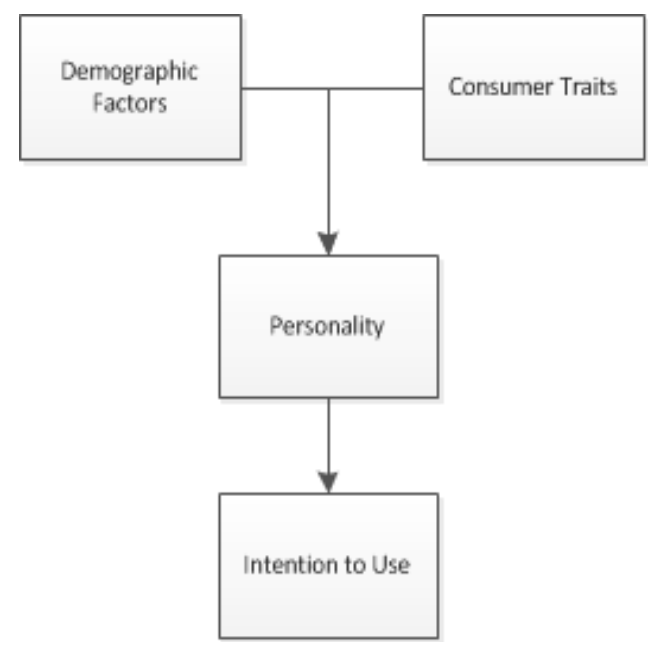

Figure 1. Theoretical contribution of research 


\subsection{Consumer Demographics}

In addition, the age of a consumer is a demographic factor which Dean (2008) suggests may have a negative effect on the preference for SCO over staff interaction. Dean (2008) builds upon findings that older customers may have a tendency to avoid SST's because of a lack of confidence in their ability to use the technology, a desire of human interaction, and a belief that the SST is there to benefit the business instead of the consumer. However this research is based on SST's as a whole and therefore cannot be entirely related to SCO specifically. This is because SST varies in purpose, design, and function and therefore one group of consumers for a certain SST (e.g., ATM), may differ completely from a group of consumers who use another SST (e.g., SCO). Some SST's have been present longer than other SST's so this would most likely have an effect on the age variable of consumers.

Other demographic factors which have been the focus of various scholarly work concerning SST and SCO include gender, education level, income level and cross-cultural factors (Dabholkar et al., 2003; Lee et al., 2010). Gender differences have been noted to have effects on technology adoption, for example women have been shown to have a higher level of computer anxiety and perceive technology as less favourable than men (Todman, 2000). Various suggestions for this behaviour include the hypothesis that women have a greater need for interaction (and therefore prefer to use a staff checkout) and men have a greater innovativeness for technology (Lee et al., 2010). However, little research into the effect of gender on usage of SCO has been carried out and a relationship between gender and usage of SCO has not yet been discovered.

Demographic factors are incorporated in various adoption literature as they are "easy to measure and readily available" (Lee et al., 2010). A study carried out by Lee et al. (2010) produced results which suggests that demographic factors only indirectly influence consumers intention to use SCO, where consumers' personality traits may arise from demographic factors and therefore have an effect on their adoption of SCO. Therefore it is important to examine individual personality traits as a possible influential factor which may affect adoption of SCO.

\subsection{Technology Anxiety and Perceived Risk}

Technology-readiness (TR) refers to the natural tendency a customer may have in embracing or using new technologies for accomplishing goals, and has been developed as a way of understanding consumer use of new technologies (Parasuraman, 2000). A factor which may affect the TR of a customer is anxiety. Computer anxiety, defined "as a feeling of being fearful or apprehensive when using or considering the use of a computer" (Leso \& Peck, 1992), can be closely linked to TR. Various studies have shown that computer anxiety is fairly common, with people suffering from different levels of anxiety (Meuter et al., 2003). Although computer anxiety is related to personal computers, this could be applied to SST's in general. Another type of anxiety perhaps more closely linked to the TR of consumers concerning SST is Technology Anxiety (TA), which is a user's negative state of mind concerning the use of technological tools (Meuter et al., 2003). The concept of TA is relevant to various technologies and this can therefore include SST's such as SCO.

\subsection{Personal Capacity and Self-Efficacy}

A consumer's personal capacity is the actual ability to carry out a task (Walker \& Johnson, 2006; Walker et al., 2002) such as successfully using SCO, and self-efficacy is the perceived ability to carry out a task (Dabholkar \& Bagozzi, 2002). If a consumer is unable, or believes they are unable, to use SCO then it is reasonable to assume that a consumer's capacity is likely to have a direct effect on their willingness to use SCO (Walker et al., 2002). Consumers with a greater self-efficacy may have more confidence in their ability to use SST's (Dabholkar \& Bagozzi, 2002), and therefore they may be more likely to use SCO than those consumers with less confidence in their ability.

\subsection{Preferred Human Interaction}

The amount of personal contact desired or preferred by a customer could influence the use of SCO (Walker et al., 2002; Dabholkar \& Bagozzi, 2002). Some people may choose to use a self-service machine specifically because it eliminates the need to interact or have contact with the staff or other customers (Curran et al., 2003; Dabholkar \& Bagozzi, 2002). NCR, the world's largest self-checkout supplier (Duluth, 2010), claims that businesses are moving from a business-to-consumer model to a consumer-to-business approach where consumers place a high value on personalised service in retail experience (NCR, 2010). Consumers may therefore choose to avoid machines because they prefer to have the human contact rather than use a machine which can be perceived as impersonal (Dabholkar \& Bagozzi, 2002; Walker et al., 2002; Dabholkar, 1996). The perceived need for human interaction could be linked to personality traits such as Extroverts and Introverts. 


\subsection{Innovativeness}

The level of innovativeness of a consumer has been accepted as a factor which may affect the attitudes towards technologies (Hirschman, 1980; Parasuraman, 2000). Inherent novelty seeking, an aspect of innovativeness, is the desire of a consumer to seek out new stimuli (Dabholkar \& Bagozzi, 2002; Hirschman, 1980) and this aspect of innovativeness could have an effect on consumer attitudes towards SCO. With the relatively recent introduction of SCO to retail stores, this new technology may excite those who have a greater novelty seeking desire to use the technology. This may encourage them to continue using SCO as they may realise the benefits SCO offer, or, on the other hand, once they have used the technology it no longer becomes a new stimuli so they may cease to use it. However the latter is unlikely as there are many other factors which may affect the continuance of use once they have adopted the technology.

\subsection{Personality Types}

Another variable that may play a role in the attitudes towards and usage of SCO is personality type. The concept of personality type was first proposed by C. J. Jung (1971) whose theory of psychological types defined six types; four basic mental processes which individuals use on a daily basis (Sensing (S), Intuition (N), Thinking (T), and Feeling (F)), as well as individual attitudes towards the inner and outer world (Extroversion (E) and Introversion (I)). Katherine Briggs and Isabel Myers developed Jung's theory to define two more distinct types; Judging (J) and Perceiving (P). These types were then split into four dichotomies/ preferences; the S-N dichotomy indicates the way in which an individual takes in information; the T-F dichotomy is the way decisions are made by the individual; the E-I dichotomy indicates where an individual's attention is focused concerning the inner and outer world; and the J-P dichotomy refers to how people deal with the outer world (Myers, 1998). The reliability and validity of the MBTI has been explored in various literatures. Michael (2003) states that because of the nature of the scoring, the MBTI produces fluctuations of reliability values and therefore leads to poor overall reliability. However, other studies have shown the MBTI to be an acceptably reliable self-report instrument (Carlyn, 1977) as well as satisfactory evidence to support the reliability of the type scores (Michael, 2003).

By understanding an individual's personality type, it may be possible to connect certain traits within the types to the attitudes towards and use of SCO. According to Myers (1998), Intuitive individuals are more inclined to focus on the future which enables them to understand abstract ideas better than Sensing individuals, who tend to focus on physical information acquired from their senses. This could indicate that Intuitive types may have a lower TA than Sensing types as they would be less anxious using technology. It may also be possible to connect other variables that could have an effect on the attitudes towards SCO (such as self-efficacy, preferred human interaction, and innovativeness) to these individual personality types

\section{Research Design}

A self-completion questionnaire was custom designed to for the research detailed in this paper. An online survey tool was used to create an attractive and user-friendly questionnaire. A link to the survey was provided and emailed to 341 students at (location removed for review). The beginning of the questionnaire included a detailed description of the purpose and aim of the study and a link to the personality type test. The questionnaire consisted of four sections, of which contained questions relating to both the literature and the objectives of the study.

\subsection{Section A-Personal Data}

Contained personal closed questions that provided important data about the respondents profile and their personality type. The use of closed questions made it easier to process the data and show relationships by comparing answers (Bryman \& Bell, 2007, p. 261). Previous literature suggests that shopper age has a negative impact on the attitudes towards and use of SCO. The first question of section A ensured that all respondents were in a certain age range (18-22 years old), which made it possible to eliminate age as a variable. As various literatures have discussed the possible effect of gender on the use of SST (Dabholkar \& Bagozzi, 2002; Dean, 2008; Lee et al., 2010), it was important to assess the gender of respondent's to ensure both male and females were represented fairly. The final part of this section explored whether respondents had used SCO before, and what personality type they were. It was important to identify differences between those who had used SCO and those who had not, as the avoidance of the technology could be linked to certain personality types. By understanding the exact personality type of a respondent, it was possible to break these down into the four dichotomies (E \& I, S \& N, $\mathrm{T} \& \mathrm{~F}, \mathrm{~J} \& \mathrm{P})$.

\subsection{Section B-Consumer Use of SCOs}

A Likert scale was used to ask respondents how likely they were to use SCO in various situations. The scale included five numbered options; never, unlikely, sometimes, likely, and always. Dabholkar (1996) identified speed 
and ease of use as critical variables concerning the usage of SST's which was important to include in the questionnaire in order to identify and analyse different factors affecting these factors (e.g., queue length, type/ quantity of item). Other factors such as payment type, which have not been considered in previous literature, were included in the questionnaire to identify the effects on consumer usage.

\subsection{Section C-Consumer Attitudes towards SCOS}

A Likert scale was used to ask respondents to rank their feelings (from strongly disagree to strongly agree) towards certain statements regarding SCO and regular tills. Various questions explored the attitudes towards technology as a whole. As TA has a negative effect on the adoption and use of SST (Meuter et al., 2003, Oyedele \& Simpson, 2007), it was important to compare the different levels of this trait with the views towards SCO of respondent's. The respondent's feelings towards human interaction were also explored within this section as this could influence the use and attitudes towards SCO (Walker et al., 2002; Dabholkar \& Bagozzi, 2002). As extroversion and introversion is a measurement of the preference for the outer world of people (Lorr, 1991), it was important to evaluate how respondent's preferences of human interaction effected their use of SCO. Dabholkar et al. (2003) hypothesised that consumers, who planned to use SCO regularly, would perceive the technology as faster, more reliable, easier to use, more enjoyable, offering more control, and prefer it to the traditional checkout. The remaining questions in section $\mathrm{C}$ related to these attributes.

\subsection{Section D-Consumer Opinions}

This section included two open-ended questions, designed to gain a qualitative view of respondents' opinions. This was useful for exploring areas that the researcher had not considered and helped to compliment the closed questions.

\section{Results and Analysis}

The data analysis involved using statistical methods in order to identify important trends and relationships within the questionnaire. Questionnaires were sent via email to a total of 341 participants, of which 60 participants responded, giving a $17.6 \%$ response rate. The questionnaire was validated so that the questionnaire could not be submitted unless all questions were answered (excluding Section D). The results show that all respondents were within the desired age range. Only $17 \%$ were under 20 years old although the difference of age is minimal and therefore should not be a significant factor. All of the respondents had used SCO before which already provides an interesting insight into the use of SCOs by 18 to 22 years old.

\subsection{Personality Types}

The results showed that almost half (48\%) of respondents have 'ESTJ' or 'ESFJ' personality types, compared to the other types which each hold under $10 \%$ of the sample. Due to the nature and size of the sample, it was decided that these 16 personality types would be broken down into the four dichotomous preferences; Introvert \& Extrovert, intuition and Sensing, Thinking and feeling, Perceiving and Judging and shown by Table 1.

Table 1. Analysis of personality types

\begin{tabular}{ll}
\hline Introvert vs. Extrovert & $\begin{array}{l}77 \% \text { of respondents have an Extrovert personality type, and } 23 \% \text { of respondents are more } \\
\text { Introverted. This is an interesting result as this may strengthen the idea that these two } \\
\text { personality types have such strong differences. For example, Extroverts are more likely to } \\
\text { respond to questionnaires than Introverts. }\end{array}$ \\
\hline Intuition vs. Sensing & $\begin{array}{l}\text { Within the sample, larger proportions were shown to have a Sensing personality type } \\
\text { compared to the } 22 \% \text { of Intuition. This could be a limitation of the research method as those } \\
\text { with intuition personality type may be either less likely to return a questionnaire, or there may } \\
\text { be less intuition types within the sample range. }\end{array}$ \\
\hline Thinking vs. Feeling & $\begin{array}{l}53 \% \text { of the sample with a Feeling personality type and } 47 \% \text { with a Thinking type. This is an } \\
\text { even spread of types. }\end{array}$ \\
\hline Perceiving vs. Judging & $67 \%$ of the sample with a Judging type and $33 \%$ with a Perceiving type. This may indicate a \\
difference in preference responding to questionnaires, or it may be that there were less \\
Perceiving types within the sample.
\end{tabular}

\subsection{Quantity of Items in Basket}

Questions were asked to establish how the number of items a customer has to purchase will affect their decision to use SCO. The results show an interesting pattern as the number of items purchasing increases, the likelihood of a 
respondent using SCO decreases. When purchasing less than 10 items, $85 \%$ of respondents stated that they were likely to use or always used SCO under these circumstances. Where almost equal amounts of respondents' state that they would never $(12 \%)$ or always $(8 \%)$ choose to use SCO when purchasing 10 to 20 items. The results also show a difference of $6 \%$ between those who were likely to choose SCO, and those who were unlikely. As the number of items increased to over 20 , there is a complete shift as $88 \%$ of respondents stated that they would never or were unlikely to choose SCO.

All Type Categories were compared to each other to examine the effect they had on a respondent's decision to use SCO when faced with the variable (number of items). The results indicate a difference between the two personality types; while $43 \%$ of Extroverts claimed they would always use SCO in this situation only 14\% of Introverts said the same. This difference of $29 \%$ is substantial compared to the other types, where differences ranged from $2 \%$ to $18 \%$. Figure 2 shows a significant difference between Introvert and Extrovert types with regards to the unlikelihood of the respondent using SCO in this situation; with $35 \%$ of Introverts unlikely to use or sometimes using SCO, compared to just $9 \%$ of Extroverts who were unlikely to use the technology. Figure 3 and Figure 4 compare Extroverts to Introverts and Intuitive to Sensing, as these showed considerable differences concerning the likelihood of using SCO. Thirty-five percent more of Introverts than Extroverts, and 35\% more of Sensing than Intuitive, claimed that they would never use SCO with more than 20 items. This shows that those respondents with Introverted Sensing types were more unlikely to use SCO than those with Extroverted Intuitive types.

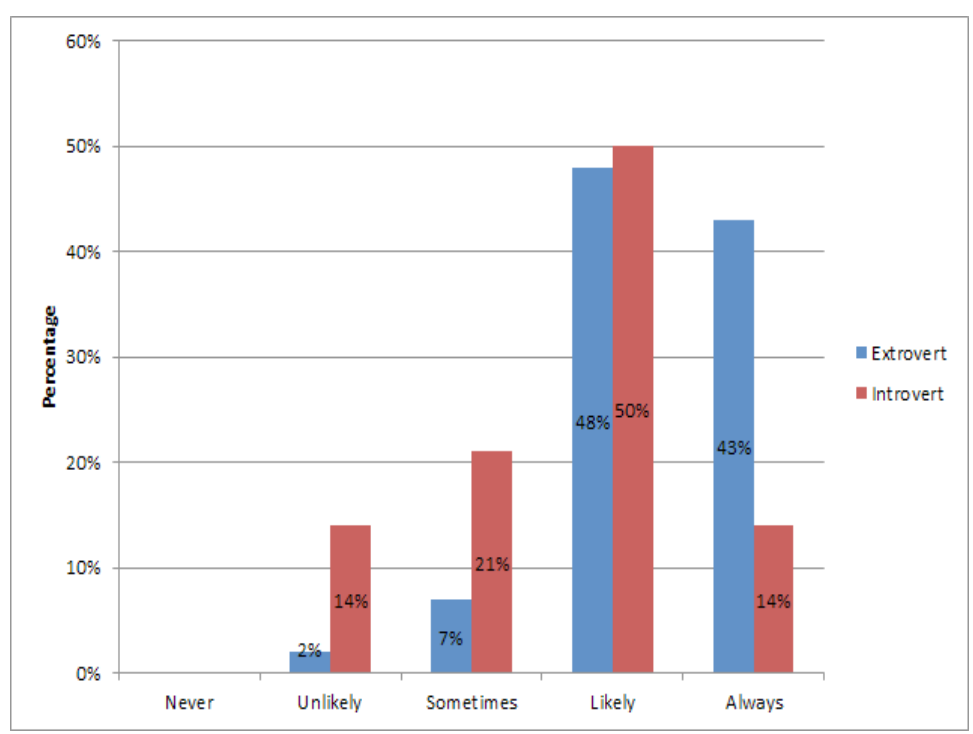

Figure 2. Percentage likelihood of respondents using SCO with less than 10 items: extroverts and introverts 


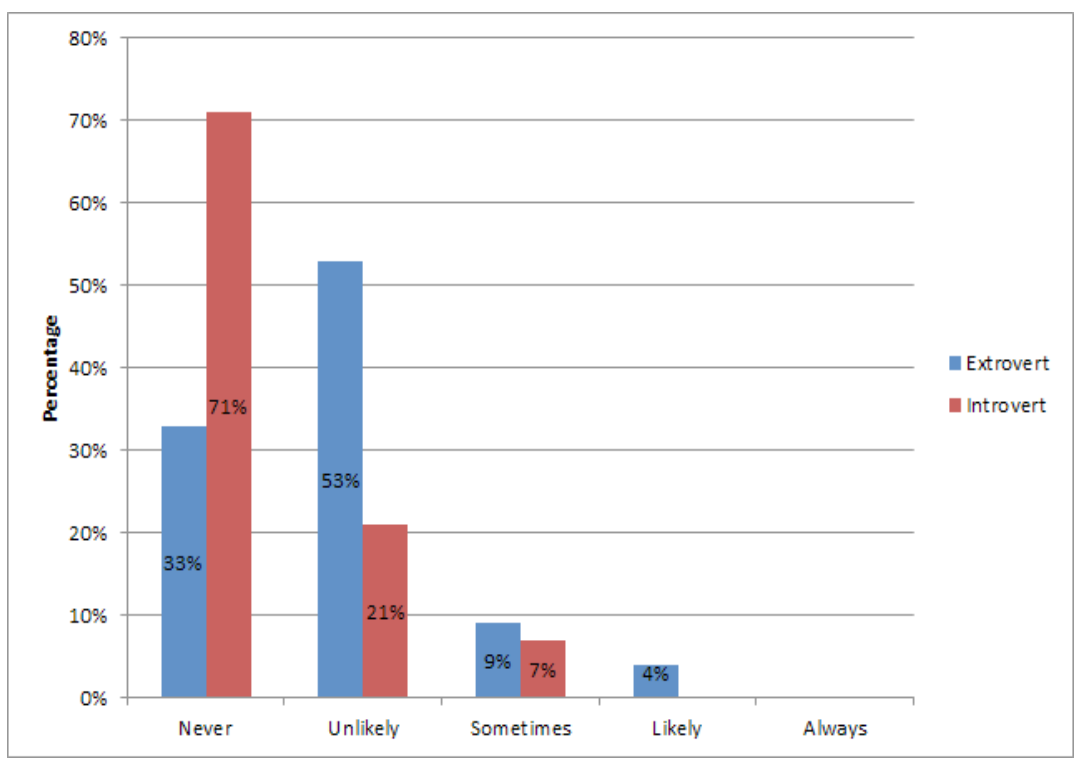

Figure 3. Percentage likelihood of respondents using SCO with more than 20 items: extroverts and introverts

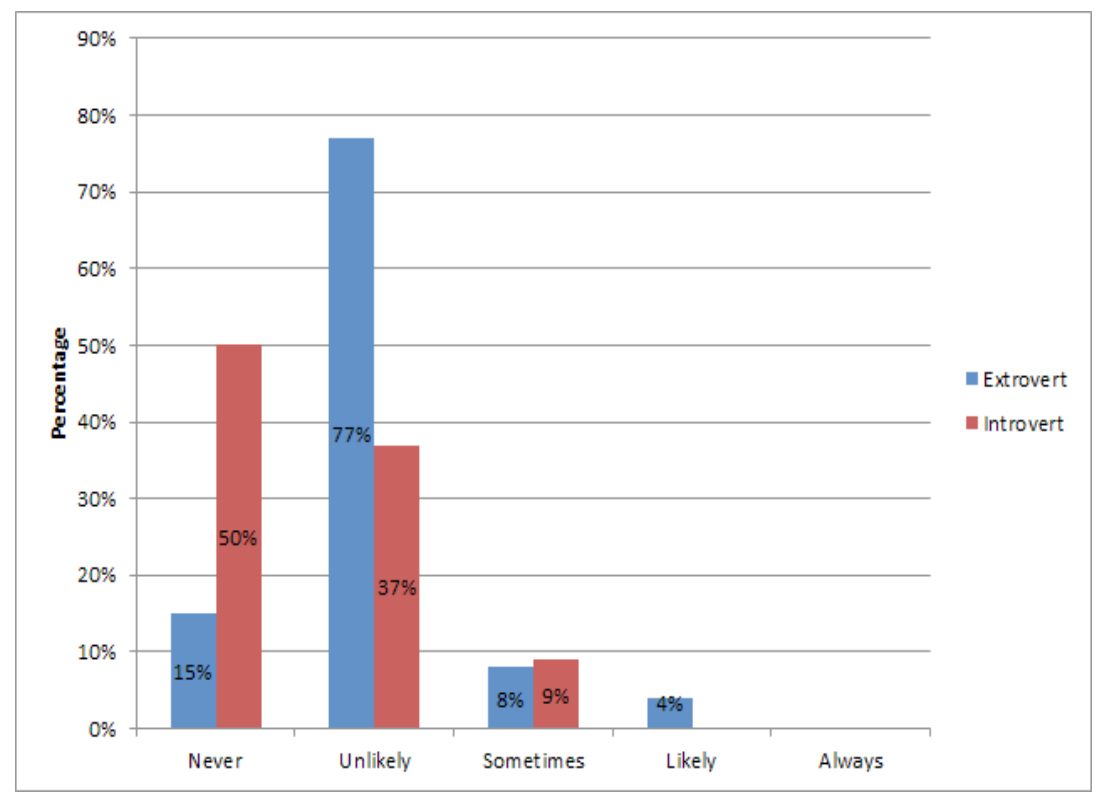

Figure 4. Percentage likelihood of respondents using SCO with more than 20 items: intuition and sensing

\subsection{Queue Length}

Questions BI to BO were concerned with the length of queue for the tills and overall the length of the queues had a large impact on a respondent's decision to use SCO or not; $89 \%$ of respondents stated they would never or were unlikely to use SCO if the queue was considerably longer for SCO than the regular till. A similar response was observed when respondents were faced with a considerably longer queue for regular till; $83 \%$ of respondents stated they would always or were likely to use SCO. When faced with no queue for both regular till and SCO, an even amount of respondent's chose unlikely, sometimes, and likely. However, $30 \%$ of respondents claimed they would always use SCO compared to only 7\% who claimed they would never use SCO in this situation. These results show that although the size of the queue has a significant effect on a respondent's decision, when faced with no queue respondents are more likely to use SCO. 


\subsection{Other Store Factors}

Questions BL to BO were concerned with the familiarity of the store, staff present, and the type of payment method used. The unfamiliarity of an SCO in a store did not appear to have any effect on respondents. This was similar to the results for an absence of staff near the SCO. The method of payment (card or cash) did not appear to have an effect on the respondent's decision to use SCO. Although over 50\% of respondents replied likely or always, slight differences to those similar in Table 1 could be seen between types. Similarities to the trend in Table 1 were also shown concerning the familiarity of the store and staff present, with significant differences between Extrovert and Introvert. Again, Introverts were shown to be much more reluctant than Extrovert to use SCO.

\subsection{Technology and SCOs}

The first two questions of this section were created to determine if a lack of knowledge or enjoyment of technology as whole had an effect on the use of SCO. The results showed that the majority of respondent's enjoyed trying new technology; the $8 \%$ which disagreed consisted mainly of Introvert, Sensing, Thinking, and Perceiving. The biggest differences between preferences were between N and S (Figure 5); where $76 \%$ of Sensing respondents slightly or strongly agreed compared to the $84 \%$ of Intuitive respondents. $84 \%$ of respondents disagreed with the statement $\mathrm{CB}$; which suggests that avoidance of SCO may be a result of a variable other than lack of knowledge about the technology.

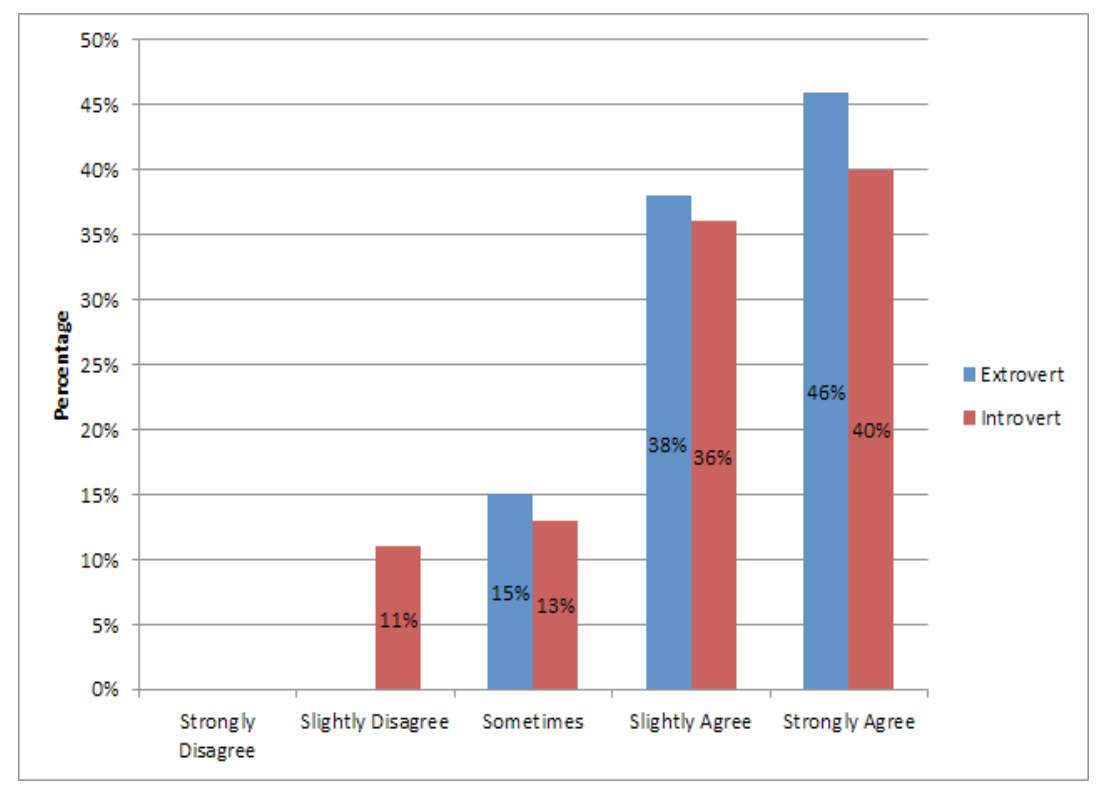

Figure 5. Respondent agreement with the statement: "I enjoy trying new technology"

\subsection{Human Interaction}

The questions in this section addressed the importance of human interaction towards the use of SCO. The results showed that an even number of respondents as a whole agreed and disagreed that they preferred to interact with a human (regular till) rather than a machine (SCO). The Thinking and Feeling types displayed the biggest differences, as shown in Figure 6, where although similar percentages of respondents chose strongly disagree/agree, a considerable difference was noted concerning slightly agree/disagree answers. Overall, a higher percentage of Feeling types (43\%) agreed that they preferred human interaction rather than machine interaction, compared to $39 \%$ of Thinking types who disagreed. 


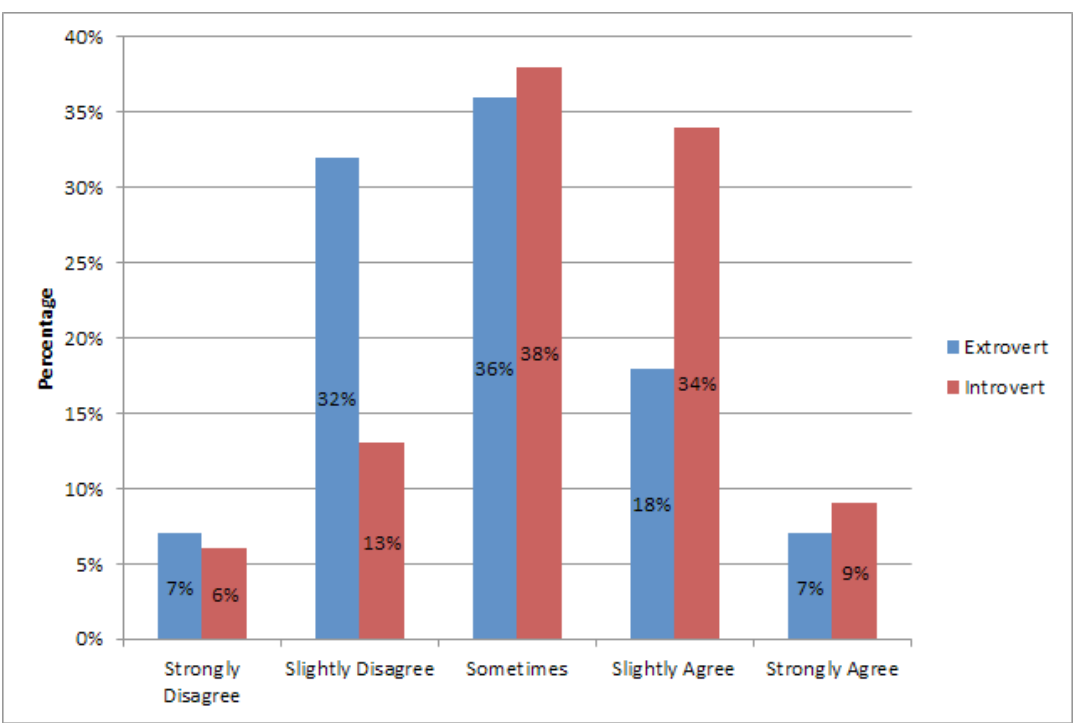

Figure 6. Respondent agreement with the statement: "I prefer to interact with a cashier than use a machine"

Questions $\mathrm{CE}, \mathrm{CF}$, and $\mathrm{CH}$ explored into possible reason why respondents preferred or did not prefer human contact. The majority of respondents as a whole did not prefer to use regular tills because of the service, nor did they prefer to use the regular till because of job losses. The majority of respondents also disagreed that they preferred to use $\mathrm{SCO}$ because of unfriendly/inefficient staff.

When comparing these statements, respondents with Feeling types appeared to be effected slightly more than those with Thinking types, as a higher percentage of Thinking types disagreed with all three statements. Extroverts displayed a greater disagreement compared to Introverts towards the statements, indicating that although some Extroverts avoid human interaction, it is not because they are concerned about job losses or inefficient service.

\subsection{SCO Design}

The part of the survey concerned the design of the technology itself. Only small differences between the preferences concerning design were observed (a maximum of $10 \%$ difference), so the sample was observed as a whole. The results show a similar percentage of the sample slightly agreeing and slightly disagreeing, whereas $12 \%$ more of respondents strongly disagreed than strongly agreed with question CG. Overall, $45 \%$ of respondents disagreed that they preferred to use SCO because it is more fun/ exciting than using regular tills, compared to $35 \%$ of respondents who agreed.

The results for question CJ revealed significant differences between Sensing and Intuitive, Extrovert and Introvert, and Judging and Perceiving. Table 2 shows $11 \%$ more Intuitive types slightly/strongly agreeing, 23\% more Extroverts slightly/strongly agreeing and $25 \%$ more Perceiving slightly/strongly agreeing compared to their opposite types. The biggest difference was observed between Judging and Perceiving where $70 \%$ of Perceiving types felt that SCO was easy to use, compared to only $45 \%$ of Judging types who felt the same way. No differences were observed when comparing Thinking and Feeling types with slightly/strongly agree answers, although 6\% more Feeling types disagreed with the statement. Overall, over half of respondents agreed that they felt SCO was easy to use ( $2 \%$ strongly disagreed and $27 \%$ slightly disagreed). 
Table 2. Percentage of respondents agreeing to the statement "I feel SCO is easy to use": Comparison of personality types

\begin{tabular}{lccc}
\hline & Slightly Agree & Strongly Agree & $\begin{array}{c}\text { Total Agreeing } \\
\text { (slightly agree+strongly agree) }\end{array}$ \\
\hline Extrovert & $\mathbf{\%}$ & $\mathbf{\%}$ & 59 \\
Introvert & 39 & 20 & 36 \\
\hline Intuitive & 29 & 7 & 62 \\
Sensing & 54 & 8 & 51 \\
\hline Thinking & 32 & 19 & 54 \\
Feeling & 36 & 18 & 54 \\
\hline Perceiving & 38 & 16 & 70 \\
Judging & 50 & 20 & 45 \\
\hline Overall respondents & 30 & 15 & $\mathbf{5 4}$ \\
\hline
\end{tabular}

The results for question CK revealed a relatively equal amount of respondents agreeing or disagreeing ( $9 \%$ more respondents strongly agreed than strongly disagreed) and 35\% answering neutrally (the sometimes option). Insignificant differences were observed when comparing preferences.

\subsection{Other Factors}

The final statements concerned other possible variables effecting consumer usage and attitudes towards SCO. The results for $\mathrm{CC}$ are shown in Table 3, where a higher percentage of respondents agreed that they usually preferred SCO to regular tills. The table also shows a higher amount of Extrovert, Intuitive, and Thinking types agreeing with the statement, and a higher amount of Introvert, Sensing, Feeling, and Judging disagreeing.

Table 3. Percentage of respondents agreeing to the statement "I usually prefer SCO to regular tills"

\begin{tabular}{|c|c|c|c|c|c|c|}
\hline & $\begin{array}{l}\text { Strongly } \\
\text { Disagree }\end{array}$ & $\begin{array}{l}\text { Slightly } \\
\text { Disagree }\end{array}$ & $\begin{array}{l}\text { Total Disagreeing } \\
\text { (slightly disagree+ } \\
\text { strongly disagree) }\end{array}$ & $\begin{array}{l}\text { Slightly } \\
\text { Agree }\end{array}$ & $\begin{array}{l}\text { Strongly } \\
\text { Agree }\end{array}$ & $\begin{array}{l}\text { Total Agreeing } \\
\text { (slightly agree }+ \\
\text { strongly agree) }\end{array}$ \\
\hline & $\%$ & $\%$ & $\%$ & $\%$ & $\%$ & $\%$ \\
\hline Extrovert & 9 & 13 & 22 & 26 & 24 & 50 \\
\hline Introvert & 21 & 29 & 50 & 14 & 0 & 14 \\
\hline Intuitive & 0 & 15 & 15 & 38 & 8 & 46 \\
\hline Sensing & 15 & 17 & 32 & 19 & 21 & 40 \\
\hline Thinking & 0 & 11 & 11 & 32 & 25 & 57 \\
\hline Feeling & 22 & 22 & 44 & 16 & 13 & 29 \\
\hline Perceiving & 10 & 15 & 25 & 25 & 15 & 40 \\
\hline Judging & 13 & 18 & 31 & 23 & 20 & 43 \\
\hline Overall respondents & 12 & 17 & 29 & 23 & 18 & 41 \\
\hline
\end{tabular}

The majority of respondents disagreed with statements CL and CM; 86\% disagreed (78\% strongly, 8\% slightly) that they preferred SCO because it is easier to steal products and $83 \%$ disagreed ( $65 \%$ strongly, $18 \%$ slightly) that they felt embarrassed using SCO. When comparing the preferences, a slightly higher percentage of Judging, Intuitive, and Feeling types strongly disagreed with question CL. Thinking, Sensing, Judging, and Extrovert displayed higher percentages in strongly disagreeing with question CM. Extroverts showed the biggest differences as $74 \%$ of respondents with this type strongly disagreed that they felt embarrassed using SCO, compared to $36 \%$ of Introverts who strongly disagreed (Figure 7). 


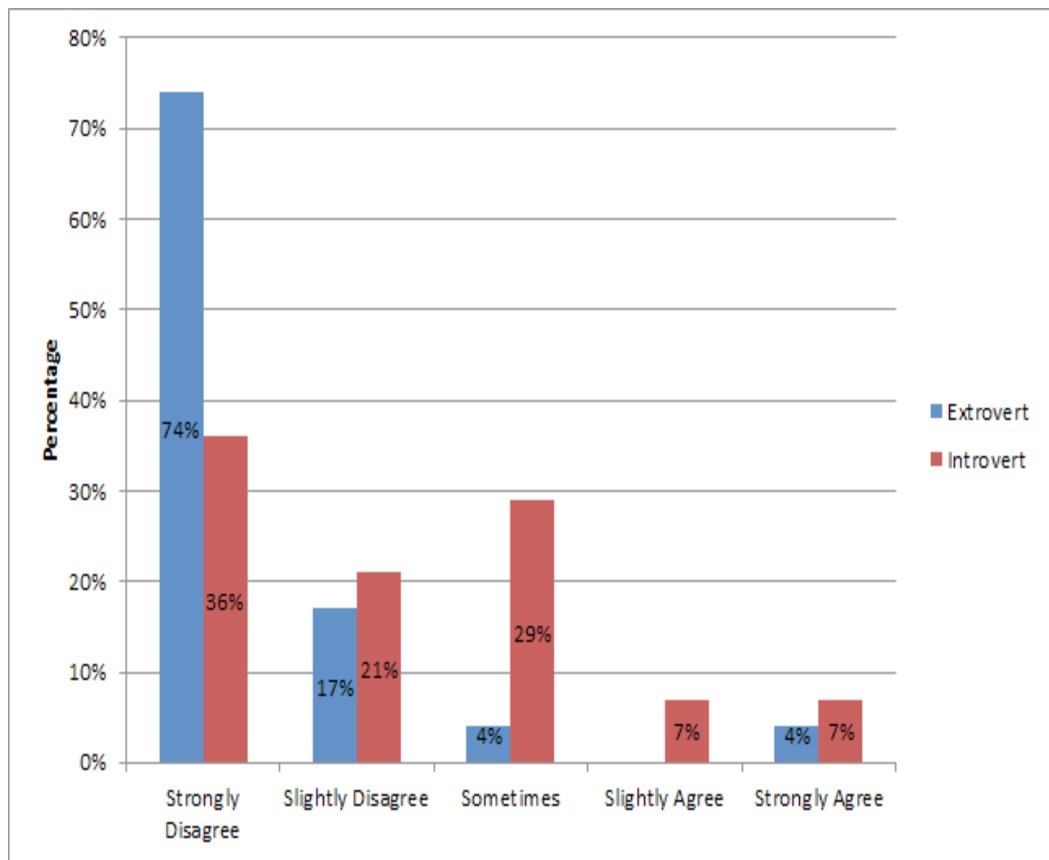

Figure 7. Respondents agreement with the statement: "I feel embarrassed using SCOs"

$62 \%$ of respondents slightly/ strongly agreed with question CI, whereas $8 \%$ strongly disagreed, $12 \%$ slightly disagreed, and $18 \%$ answered sometimes. $65 \%$ of Extroverts and 50\% Introverts slightly/ strongly agreed, a much larger amount of Extroverts (39\%) strongly disagreed than Introverts (7\%). Question CN, revealed a mixed distribution of answers from respondents as a whole, with no visible patterns. A significantly higher percentage of Perceiving and Intuitive types strongly disagreed with question CN compared to their opposites; $22 \%$ more Intuitive than Sensing, and 17\% more Perceiving than Judging.

Table 4 is a breakdown of section $\mathrm{D}$ responses. The responses were separated into 7 main categories and 18 sub categories in order to view and analyse the results effectively. Table 4 shows the amount of times certain factors were mentioned by respondents. When asked the main reasons for choosing regular till instead of SCO, the quantity of items was mentioned the most times. Respondents stated that a larger amount of items would lead them to use regular till.

When asked the main reasons for choosing SCO instead of a regular till, the speed of SCO was mentioned the most times as respondents believed it was quicker. Respondents stated that they would choose SCO if there was a shorter queue length and/ or because they believed it was generally quicker.

Overall, the issue of speed was mentioned the most times and therefore could be considered as a main reason for choosing one till over another. This was followed by the quantity of items, where respondents were likely to choose SCO with a small number of items, and choose regular tills with a larger number of items

Table 4. Respondent's main reasons for avoiding / choosing to use SCOs

\begin{tabular}{|c|c|c|c|}
\hline \multirow[t]{2}{*}{ Influential Factors } & $\begin{array}{l}\text { Choosing regular till over } \\
\text { SCO }\end{array}$ & $\begin{array}{l}\text { Choosing SCO over } \\
\text { regular till }\end{array}$ & \multirow[t]{2}{*}{ Total } \\
\hline & \multicolumn{2}{|c|}{ (Number of times mentioned) } & \\
\hline Items & 22 & 16 & 38 \\
\hline - $\quad$ Large number of goods & 17 & 0 & \\
\hline Small number of goods & 0 & 16 & \\
\hline Items requiring authorisation & 5 & 0 & \\
\hline Easier & 8 & 9 & 17 \\
\hline - In general & 3 & 2 & \\
\hline To use & 5 & 7 & \\
\hline Quicker & 19 & 44 & 63 \\
\hline - $\quad$ Generally & 8 & 21 & \\
\hline - $\quad$ Queuelength & 11 & 23 & \\
\hline
\end{tabular}




\begin{tabular}{|c|c|c|c|c|}
\hline \multicolumn{2}{|c|}{ Staff } & 12 & $\mathbf{0}$ & 12 \\
\hline- & Humaninteraction & 7 & 0 & \\
\hline- & Job Loss & 5 & 0 & \\
\hline \multicolumn{2}{|c|}{ Convenient } & 13 & 5 & 18 \\
\hline- & General & 4 & 3 & \\
\hline- & Laziness / less effort & 5 & 0 & \\
\hline- & Near Exit & 0 & 2 & \\
\hline- & More room to pack bags & 4 & 0 & \\
\hline \multicolumn{2}{|c|}{ Alternative is annoying / irritating } & 13 & 3 & 16 \\
\hline- & General & 6 & 3 & \\
\hline- & SCO weighing system & 4 & 0 & \\
\hline- & Not easy to use & 3 & 0 & \\
\hline \multicolumn{2}{|c|}{ Other } & 8 & 12 & 20 \\
\hline- & General & 8 & 7 & \\
\hline- & Fun / enjoyment & 0 & 5 & \\
\hline
\end{tabular}

\section{Discussion}

Various factors were found to effect consumers, some more than others, in different ways according to their personality types. Some resultant behaviours were more affected by underlying personality types than others, and some of the differences were perhaps affected by the nature of the situation. Consumer attitudes toward using SCO were extremely varied; some avoided the technology at all times, and some used the technology regardless of most circumstances. The results found significant differences between personality types regarding the attitudes and use of SCO. Although these types did have an effect, some other factors also appeared to have consequences on the consumer's usage and attitude toward SCO.

\subsection{Technology and SCO}

The majority of respondents admitted that they enjoyed trying new technology, with the highest percentage being Intuitive types. This was interesting as the enjoyment of trying new technology has led to the adoption of SCO, as all respondents admitted to using the technology. It was also interesting to discover that Introverts enjoyed trying technology the most, as this matches their description ("enjoyment of challenges") from Myers \& Briggs (n.d.) accurately.Although the research revealed avoidance of SCO for various reasons, a lack of understanding of the technology itself was not one of these reasons. Previous literatures have implied that TA has a negative effect on the intention to use SCO; however, respondents from the study did not reveal any indication of TA. The age range of respondents included 18 to 22 years old, a relatively young sample, which may be the reason for lack of TA as the findings from Lee et al. (2010) suggest that younger consumers tend to have a lower TA than older consumers.

The majority of respondents agreed that they found SCO easy to use and as respondents admitted to the continued use of SCO, this compliments the findings of Davis et al. (1989) and the TAM, where a perceived ease of use and perceived usefulness leads to adoption and use of technology. A higher percentage of Perceiving types perceived SCO as easy to use, which may be because Perceiving types have higher self-efficacy than the other types. Although some respondents referred to the SCO weighting system as "annoying", the majority of respondents did not avoid SCO because of this. This was the same for the method of payment, as both tills offer the same options.

\subsection{Speed}

The study clearly confirmed findings from Bateson (1985), which suggests that the speed of an SST is an important factor for consumers, particularly SCO (Anselmsson, 2001). The majority of respondents believed SCO to be quicker than regular tills, and still continued to use the technology even when presented with no queue for either till. This also confirmed findings from Alpert (2008) who suggests that speed is the main reason for choosing SCO over regular tills (Dabholkar \& Bagozzi, 2002). However, taking into consideration that all respondent's admitted using SCO, the $20 \%$ that disagreed that they used SCO because it's quicker must use SCO for reasons other than speed.

The queue length of a till had a significant effect on the attitudes and use of the technology. The results showed that the majority of respondents avoided the till with the longest queue, which indicates a negative impact of queue length/ perceived waiting time on the use of both regular till and SCO. However, a significantly longer queue for a particular till, for example SCO, may not necessarily result in a longer waiting time. Queues for SCO can be longer than regular tills, but have shorter waiting times, as consumers using the technology usually purchase a small number of items. This suggests that although consumers look for short queues to minimise waiting time (Wang et al., 2009), the perceived waiting time may differ from the actual waiting time. 


\subsection{Nature of Items in Basket}

The quantity of items that a consumer planned to purchase had a significant impact on their decision to use SCO. When purchasing a larger quantity of items, consumers tended to avoid SCO and use regular tills as some respondents believed that the design of the SCO made it difficult to use; most SCO's are designed for baskets only and do not have the space for a trolley or a conveyer belt. Respondents were most likely to use SCO when purchasing less than 10 items. Extroverts were much more likely to use SCO, and as the number of items increased Introverts and Sensing types were much more reluctant to use SCO than the other types.

Respondents were more likely to use SCO when purchasing embarrassing items, which is likely to be related to the 'avoidance of personnel' (Meuter et al., 2000) where consumers will avoid regular tills to avoid staff. This is because SCO gives consumers a certain amount of privacy which means they could purchase embarrassing products without anyone knowing. The results surprisingly showed Introverts as less likely to use SCO than Extroverts in this situation. However, this may be because of the fear of something 'going wrong' with the SCO and therefore drawing the attention of others.

Overall, respondents tended to avoid SCO when purchasing bulky items which was mainly due to the design of the technology, and could also be the result of consumer laziness. Other item types such as loose fruit and vegetables, DVD's, and items needing authorisation did not seem to have any significant effects on consumer decisions to use SCO. However, a number of respondents mentioned how items that needed authorisation slowed down the process when using SCO, as an attendant had to be called.

\subsection{Human Interaction}

Dabholkar (1996) and Lee et al. (2010) agree that personal contact is important to those consumers with a high need for interaction. Dabholkar's (1996) study showed that those who had a high need for interaction avoided SST's, and those with a low need for interaction were more likely to use an SST. This compliments the findings as Feeling types, who are described as 'people orientated' (Briggs-Myers \& Briggs, n.d.), were shown to have a higher preference for human interaction and a higher likelihood of avoiding SCO. Thinking types, who are described as 'detached' (Briggs-Myers \& Briggs, n.d.), were shown to have a lower preference for human contact and a higher preference for using SCO. This compliments various findings which suggest the need for human interaction has a negative effect on the intention to use SCO (Dabholkar, 1996; Dabholkar \& Bagozzi, 2002; Lee et al., 2010; Walker et al., 2002). Dabholkar (1996) also mentions that some consumers value human interaction above anything else concerning SST's, which may be the case for Feeling types.

\subsection{Personality Types}

Throughout the results analysis, Extrovert, Intuitive, Thinking, and Perceiving types were the more likely to use SCO than their opposites (Introvert, Sensing, Feeling, Judging). This was particularly evident from the response to the statement 'I prefer SCO to regular till', where Extrovert, Intuitive, Thinking, and Perceiving agreed the most. A significantly high percentage of Thinking types preferred SCO to regular till, which suggests that no matter what situation they are faced with, will most likely to use SCO.

Taking these four individual preferences into consideration, this suggests that respondents with ENTP types are the most likely out of all the personality types to use SCO, compared to ISFJ types who are the least likely to use SCO. Some factors had a greater effect on types than others; feeling types had a greater need for human interaction than the other preferences and Extroverts felt the least embarrassed using SCO. When comparing some of the situations to the individual preference type descriptions (Table 1, p. 19), it was interesting to discover that the descriptions often matched the response of a respondent's answer. For example, the results showed that Perceiving types, who are described as 'spontaneous, flexible, and quick to adapt to changing conditions' (Briggs-Myers \& Briggs, n.d.), enjoyed using SCO the most. As SCO is still a relatively new technology, it can be assumed that one reason why Perceiving types enjoy the technology is because they keep their options open and choose to adapt and use the technology (SCO).

\subsection{Recommendations}

Table 5 includes a number of recommendations based on the above analysis that could be used by both consumers and retailers in order to understand and improve the use of SCOs. 
Table 5. Recommendations arising from this study of 18-22 years old

\begin{tabular}{|c|c|c|}
\hline Recommendation & Description & Evaluative Comments \\
\hline $\begin{array}{l}\text { The design of SCO could be improved } \\
\text { to allow for a larger amount of items to } \\
\text { be purchased. }\end{array}$ & $\begin{array}{l}\text { This could include designing SCO so } \\
\text { that consumers are more confident } \\
\text { using the machine for a larger quantity } \\
\text { of items. This could include SCO's } \\
\text { with conveyor belts, automatic } \\
\text { scanning, and more space for placing } \\
\text { bags. The baggage area could also be } \\
\text { improved so that it allows more room } \\
\text { for bags, as well as a more } \\
\text { user-friendly weighing system. }\end{array}$ & $\begin{array}{l}\text { SCO's designed specifically for } \\
\text { trolleys and large amounts of items } \\
\text { have already been introduced in } \\
\text { America. For example, NCR's } \\
\text { 'Fastlane' SCO includes a conveyor } \\
\text { belt and a large bagging area. } \\
\text { Improvements to SCO have also lead } \\
\text { to the invention of new technology } \\
\text { such as a chip which could be placed } \\
\text { on all items, which would be scanned } \\
\text { automatically as a consumer exits. }\end{array}$ \\
\hline Improve human interaction. & $\begin{array}{l}\text { Retailers could improve consumer } \\
\text { experience of human interaction } \\
\text { within the store by introducing more } \\
\text { staff at SCO to help and assist } \\
\text { consumers. They could also introduce } \\
\text { better staff training to improve } \\
\text { customer service. }\end{array}$ & $\begin{array}{l}\text { Most retailers now assign a member of } \\
\text { staff at the SCO, who offers to show } \\
\text { people how to use SCO, as well as } \\
\text { assisting consumers with the } \\
\text { technology. However, in busy } \\
\text { situations, gaining the attention of the } \\
\text { one member of staff can slow the } \\
\text { process of the transaction down. More } \\
\text { members of staff in busy periods } \\
\text { would improve the human interaction } \\
\text { for consumers, especially if they were } \\
\text { trained effectively in customer } \\
\text { service. }\end{array}$ \\
\hline $\begin{array}{l}\text { Encourage customers with trolleys to } \\
\text { use the regular tills, and those with } \\
\text { baskets to use SCO. }\end{array}$ & $\begin{array}{l}\text { Some customers with trolleys } \\
\text { sometimes use } \mathrm{SCO} \text {, which slows the } \\
\text { process as the technology is not } \\
\text { designed for purchasing a large } \\
\text { quantity of items. }\end{array}$ & $\begin{array}{l}\text { Having a member of staff who directs } \\
\text { customers to the appropriate till would } \\
\text { encourage an effective use of the tills } \\
\text { and speed up the process. The member } \\
\text { of staff could also analyse the situation } \\
\text { concerning the items a consumer has } \\
\text { and compare this to the queues for the } \\
\text { tills. }\end{array}$ \\
\hline
\end{tabular}

\section{Conclusion}

The main aim of the research was to gain a better understanding of consumer attitudes towards and the use of SCO in retail concerning personality types. There was sufficient literature to conclude that a variety of variables and situational factors affect consumers' attitudes and use of SST and SCO; however a gap in the research existed regarding the effects of personality type and the effect of some situational factors. This created the foundation for this project; a unique in-depth view into the effects of personality types, using Jung's (1971) psychological preferences and the MBTI, on consumer usage and attitudes towards SCO.

The adoption of SCO carries several benefits for both consumers and retailers and analysing the behaviour behind their use and their uptake will enable retailers to maximise the return on the cost of investing in SCO. The findings outlined in Table 5 will help to improve the customer experience of shopping in store and this would ultimately help lead to future loyalty. Adopting the measures in Table 5 would also help to improve efficiency and speed at the during the checkout process. Perhaps the most important measure shown is actually stopping customers who would not be suitable for SCO (either by the products they have chosen or technical ability). There is the initial outlay for the SCO tills, but this is outweighed by the cost savings from fewer till staff. There is an issue regarding trust and theft of products, especially as some respondents used SCO for the very reason it appears easier to steal products. It is not possible to ascertain from the data collected whether respondents had actually gone through with theft from an SCO, which is very different from ticking a box in a survey.

There are several limitations to this study, although most actually represent opportunities for further research. The main limitation is the restriction of the findings of this research to the age group of 18-22 years old, and all of 
whom share more demographic characteristics. To understand the true benefit and uptake of SCO for retailers, a more comprehensive survey would need to be undertaken utilising a range of survey techniques (i.e. not just online) and at a range of locations and across a larger age range. This research does however provide a solid foundation for this extension and demonstrates that significant, and useful, insights can be gained from the analysis of personality types that use SCO. Along with expanding the research to address the limitations, other exciting opportunities exist to extend this research in other directions: the use of hand held scanners as shoppers move around the store could be affected by personality types differently than $\mathrm{SCO}$ and a comparison with online shopping behaviours would undoubtedly yield interesting findings.

\section{References}

Alpert, G. C. (2008). The self-service "buy-and-pay" market: kiosk, vending and foodservice trends in the US. Retrieved from http://academic.marketresearch.com/

Anselmsson, J. (2001). Customer-perceived service quality and technology-based self-service. Lund: Lund Business Press, Lund University.

Briggs-Myers, I., \& Briggs, K. C. (n.d.). Myers-Briggs Type Indicator. Retrieved from Myers Briggs: http://www.psikologi.tarumanagara.ac.id/arsip/MBTI-General-Information.pdf

Bryman, A., \& Bell, E. (2007). Business research methods. Oxford: Oxford University Press.

Carlyn, M. (1977). An assessment of the Myers-Briggs Type Indicator. Journal of Personality Assessment, 4(1), 461-473. http://dx.doi.org/10.1207/s15327752jpa4105_2

Dabholkar, P. (1996). Consumer Evaluations of new technology-based self-service options: an investigation of alternative models of service quality. Internation Journal of Research in Marketing, 13(1), 29-51. http://dx.doi.org/10.1016/0167-8116(95)00027-5

Dabholkar, P., \& Bagozzi, R. (2002). An attitudinal model of technology-based self-service: moderating effects of consumer traits and situational factors. Journal of the Academy of Marketing Science, 30(3), 184-201. http://dx.doi.org/10.1177/0092070302303001

Dabholkar, P., Bobbit, L., \& Lee, E. J. (2003). Understanding consumer motivation and behaviour related to self-scanning in retailing: Implications for strategy and research on technology-based self-service. International Journal of Service Industry Management, 14(1), 59-95. http://dx.doi.org/10.1108/09564230310465994

Davis, F. D., Bagozzi, R. P., \& Washaw, P. R. (1989). User acceptance of computer technology: a comparison of two theoretical models. Management Science, 35(8), 982-1003.

Dean, D. (2008). Shopper age and the use of self-service technologies. Managing Service Quality, 18(3), 225-238. http://dx.doi.org/10.1108/09604520810871856

Duluth, G. (2010). Survey: NCR is world's largest self-checkout supplier. Retrieved from Chain Store Age: $\mathrm{http}: / /$ www.chainstoreage.com/story.aspx?id=152739\&type=web

Hirschman, E. (1980). Innovativeness, Novelty Seeking, and Consumer Creativity. The Journal of Consumer Research, 7(3), 283-295.

Jung, C. (1971). Psychological Types (Vol. 6). NJ: Princeton University Press.

Lee, H., Cho, H., Xu, W., \& Fairhurst, A. (2010). The influence of consumer traits and demographics on intention to use retail self-service checkouts. Marketing Intelligence \& Planning, 28(1), 45-58. http://dx.doi.org/10.1108/02634501011014606

Leso, T., \& Peck, K. (1992). Computer anxiety and different types of computer courses. Journal of Educational Computing Research, 8(4), 469-478.

Lorr, M. (1991). An emprirical evaluation of the MBTI typology. Personality and Individual Differences, 12(11), $1141-1145$.

Makarem, S., Mudambi, S., \& Podoshen, J. (2009). Satisfaction in technology-enabled service encounters. Journal of Services Marketing, 23(3), 134-144. http://dx.doi.org/10.1108/08876040910955143

Meuter, M., Ostrom, A., Bitner, M., \& Roundtree, R. (2003). The influence of technology anxiety on consumer use and experiences with self-service technologies. Journal of Business Research, 56(11), 899-906. http://dx.doi.org/10.1016/S0148-2963(01)00276-4 
Meuter, M., Ostrom, A., Roundtree, R., \& Bitner, M. (2000). Self-service technologies: understanding customer satisfaction with technology-based service encounters. Journal of Marketing, 64(3), 50-64. http://dx.doi.org/10.1509/jmkg.64.3.50.18024

Myers, I. B. (1998). Introduction to type. CA: Consulting Psychologists Press, Inc.

Oyedele, A., \& Simpson, P. (2007). An empirical investigation of consumer control factors on intention to use selected self-service technologies. International Journal of Service Industry Management, 18(3), $287-306$. http://dx.doi.org/10.1108/09564230710751497

Parasuraman, A. (2000). Technology readiness index (TRI): a multiple item scale to measure readiness to embrace new technologies. Journal of Service Research, 2(4), 207-320. http://dx.doi.org/10.1177/109467050024001

Retail Banking Research. (2009). Self-checkout to drive growth in EPOS hardware spending. Retail Automation Bulletin, 1(1), 1-19.

Venkatesh, V., \& Bala, H. (2008). Technology Acceptance Model 3 and a research agenda on interventions. Decision Sciences, 39(2), 273-315. http://dx.doi.org/10.1111/j.1540-5915.2008.00191.x

Walker, R., \& Johnson, L. (2006). Why consumers use and do not use technology-enabled services. Journal of Services Marketing, 20(2), 125-135. http://dx.doi.org/10.1108/08876040610657057

Walker, R., Craig-Lees, M., Hecker, R., \& Francis, H. (2002). Technology-enabled service delivery: an investigation of reasons affecting customer adoptionand rejection. International Journal of Service Industry Management, 13(1), 91-106. http://dx.doi.org/10.1108/09564230210421173

Wang, C., Harris, J., \& Patterson, P. (2009). Situational influences in the choice of self-service in a multi-channel retail context. Retrieved from Diskbank: http://www.duplication.net.au/ANZMAC09/papers/ANZMAC2009-261.pdf

Webster, M. (2009). Self-Checkout: the global growth story. Retail Automation Bulletin, 1(1), 1-20.

\section{Copyrights}

Copyright for this article is retained by the author(s), with first publication rights granted to the journal.

This is an open-access article distributed under the terms and conditions of the Creative Commons Attribution license (http://creativecommons.org/licenses/by/3.0/). 